\title{
Correction to: The impact of psychological identification with home-name stocks on investor behavior: an empirical and experimental investigation
}

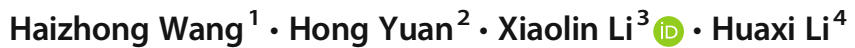

Published online: 13 September 2019

(C) Academy of Marketing Science 2019

\section{Correction to: Journal of the Academy of Marketing Science} https://doi.org/10.1007/s11747-019-00677-3

The original version of this article unfortunately contains a mistake. The labels on the $\mathrm{x}$-axis of Figure $3 \mathrm{a}$ and $3 \mathrm{~b}$ are incorrect. Kindly see below the correct Figure 3.
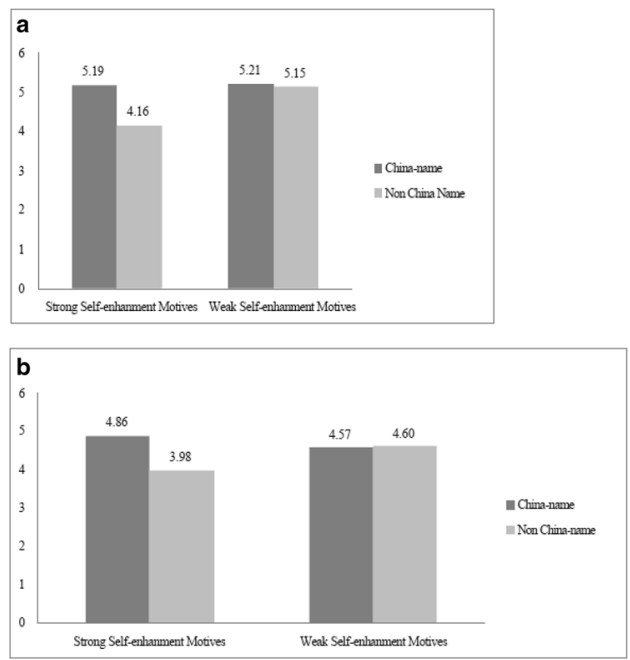

The online version of the original article can be found at https://oi.org/10. 1007/s11747-019-00677-3

\section{Xiaolin Li}

xiaolinli@gdufe.edu.cn

\section{Haizhong Wang}

wanghzh@mail.sysu.edu.cn

Hong Yuan

hongy@uoregon.edu

1 The School of Management, Sun Yat-sen University, 135 Xinggang Road, Haizhu District, Guangzhou 510275, China
Publisher's note Springer Nature remains neutral with regard to jurisdictional claims in published maps and institutional affiliations. 